\title{
Proton magnetic resonance spectroscopy in Parkinson's disease and progressive supranuclear palsy
}

\author{
F Federico, I L Simone, V Lucivero, M De Mari, P Giannini, G Iliceto, D M Mezzapesa, \\ P Lamberti
}

\begin{abstract}
Objectives-Proton magnetic resonance spectroscopy ( ${ }^{1} \mathrm{H}-\mathrm{MRS}$ ) localised to the lentiform nucleus, was carried out in eight patients with idiopathic Parkinson's disease and five patients with progressive supranuclear palsy. The aim of the study was to assess the concentration of $\mathbf{N}$ acetyl-aspartate (NAA), creatine and phosphocreatine ( $\mathrm{Cr}$ ), and choline containing compounds (Cho) in the putamen and globus pallidus of these patients.

Methods-Peak ratios obtained from patients were compared with those from nine healthy age matched controls.

Results-NAA/Cho and NAA/Cr ratios were reduced significantly in patients with progressive supranuclear palsy.

Conclusion-These results suggest an NAA deficit, due to neuronal loss, in the lentiform nucleus of these patients. ${ }^{1} \mathrm{H}-$ MRS is a non-invasive technique that can provide useful information concerning striatal neuronal loss in the basal ganglia of patients with parkinsonian syndromes.
\end{abstract}

(F Neurol Neurosurg Psychiatry 1997;62:239-242)

Keywords: magnetic resonance spectroscopy; Parkinson's disease; progressive supranuclear palsy

The pathology of idiopathic Parkinson's disease is characterised by degenerative changes in the pars compacta of the substantia nigra, leading to a reduction of striatal dopamine. Other parkinsonian syndromes include additional degenerative changes affecting other basal ganglia structures. In progressive supranuclear palsy, neuronal loss involves the globus pallidus, subthalamic nucleus, dentate nucleus, substantia nigra, and other mesencephalic nuclei. ${ }^{1}$ In the striatonigral variety of multiple system atrophy the areas chiefly affected are the putamen, subthalamic nucleus, substantia nigra, pontine nuclei, inferior olives, and cerebellar cortex. ${ }^{2}$ The clinical differential diagnosis between these parkinsonian syndromes is often very difficult, particularly in the early stage. Even MRI and PET can fail to demonstrate specific changes in these patients. ${ }^{3-6}$

Proton magnetic resonance spectroscopy ('H-MRS) is a recently developed non-invasive technique that allows the presence and concentration of certain brain metabolites to be measured in vivo. ${ }^{1} \mathrm{H}-\mathrm{MRS}$ at a long echo time (TE) of $135 \mathrm{~ms}$ detects metabolites with long T2 relaxation times. The signal at $2 \cdot 0$ ppm is primarily from $\mathbf{N}$-acetyl-aspartate (NAA), an amino acid present in the brain almost exclusively in neurons and in their processes $^{7-10}$; the signal at $3.0 \mathrm{ppm}$ is from creatine and phosphocreatine (Cr) compounds, which are involved in membrane biosynthesis and breakdown ${ }^{7}$; and the signal at $3.2 \mathrm{ppm}$ is from choline containing compounds (Cho), which are cell membrane constituents. ${ }^{78}$ The lactate (lac) signal at $1.33 \mathrm{ppm}$ is usually an index of anaerobic metabolism. ${ }^{811}{ }^{1} \mathrm{H}-\mathrm{MRS}$ has been utilised, measuring areas underlying spectral peaks, in different neurological disorders-namely, tumours, ${ }^{12}{ }^{13}$ stroke, ${ }^{14-16}$ multiple sclerosis, ${ }^{1718}$ AIDS and HIV related disorders, ${ }^{1920}$ and neurodegenerative disorders such as Huntington's disease and Alzheimer's disease..$^{21} 22$

Recently this technique has also been used in the study of parkinsonian disorders, localising the volume of interest to the basal ganglia. ${ }^{23-27}$ In particular, Holshouser and coworkers, in a large series, did not find any significant difference between patients with idiopathic Parkinson's disease and normal subjects. ${ }^{26}$ On the other hand a significant reduction in the NAA/Cr ratio in the lentiform nucleus was found by Davie et al in patients with the striatonigral atrophy variety of multiple system atrophy and also, to a lesser degree, in patients with the olivopontocerebellar atrophy variety. ${ }^{23}$ Other parkinsonian syndromes such as idiopathic Parkinson's disease have not yet been examined with this technique.

In this study we performed ${ }^{1} \mathrm{H}-\mathrm{MRS}$, localised to the lentiform nucleus, in two groups of patients: (1) patients with idiopathic Parkinson's disease, (2) patients with progressive supranuclear palsy, to assess $\mathrm{NAA}, \mathrm{Cr}$, and Cho striatal levels.

\section{Methods and subjects}

MRI and ${ }^{1} \mathrm{H}$-MRS were carried out with a whole body $1.5 \mathrm{~T}$ iron shielded system (Magnetom Siemens) using a standard circularly polarised head coil. The imaging protocol consisted of sagittal $\mathrm{T} 1$ weighted spin echo sequences (TR $600 \mathrm{~ms}$ and TE $15 \mathrm{~ms}$ ) and coronal and transverse $T 2$ weighted sequences (TR $2200 \mathrm{~ms}$ and TE $80 \mathrm{~ms}$ ) to obtain the best resolution of basal ganglia. Slice thickness was $5 \mathrm{~mm}$ and the matrix $256 \times 256$. After global shimming, performed with a standard non-selective shimming sequence, a volume of interest of $3.4 \mathrm{ml}$ was localised to the lentiform nucleus; this was done on both sides whenever 


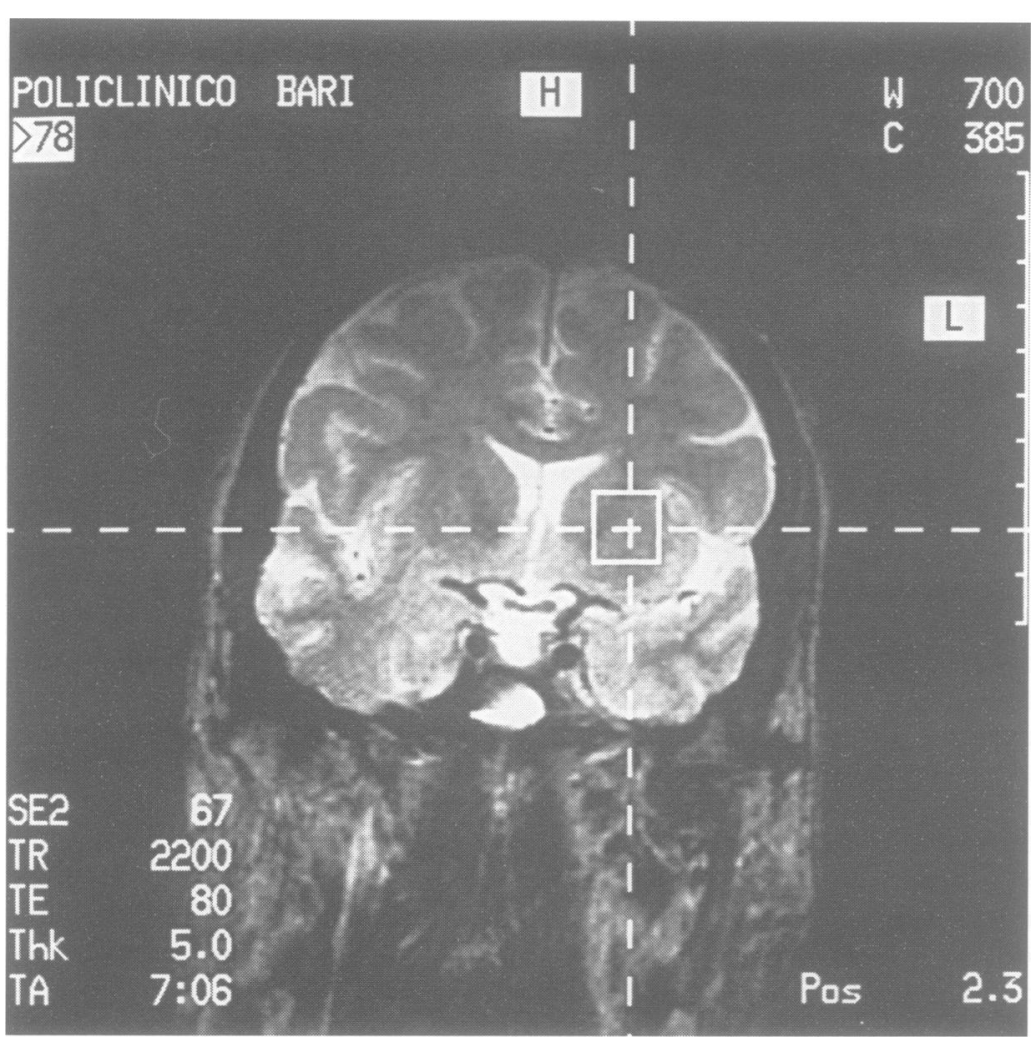

Figure 1 T2 weighted spin echo (TR $2200 \mathrm{~ms} T E 80 \mathrm{~ms}$ ) coronal image from a control subject showing the spectroscopic volume of interest centred on the left putamen and globus pallidus. have a very short $\mathrm{T} 2$, and also allows acquisition of a signal from lactate methyl groups in antiphase condition doublet (spin-spin coupling constant (J) $7 \cdot 35 \mathrm{~Hz}$ ).

It is difficult to measure absolute values with our technique; therefore, the results are obtained in terms of ratios of metabolite signals. Ratios between areas underlying metabolite spectral peaks (NAA/Cho, NAA/Cr, $\mathrm{Cho/Cr}$ ) have been utilised.

During the period December 1994November 1995 we studied three groups of patients. Group A comprised eight patients with idiopathic Parkinson's disease, mean (SD) age $60.0(7 \cdot 8)$ years, mean disease duration 7 (range 4-12) years. All patients were taking levodopa (mean daily dosage: 275, range $150-400 \mathrm{mg}$ ). Mean Hoehn and Yahr stage was 2. Group B comprised five patients with progressive supranuclear palsy with a mean age of $71.4(3.3)$ years. The diagnosis of progressive supranuclear palsy was made according to the criteria of Golbe et $^{3 l^{30}}$ : age at onset $>40$ years; rapid progression of the disease, bradykinesia, gaze palsy, and at least three of the following symptoms: dysarthria, dysphagia, axial rigidity with hyperextended neck, no or mild tremor, frequent falls, and pyramidal signs. None of these patients had cerebellar or autonomic signs or evidence of polyneuropathy. Mean duration of disease was $5(1 \cdot 87)$ (range 3-8) years.

All patients from groups A and B were seen regularly as outpatients at the movement disorder clinic of the Institute of Neurology, University of Bari. The control group comprised nine healthy age matched (mean age 63.4 (8.9) years) subjects. Structural MRI images were studied by an experienced neuroradiologist. Brain MRI findings were in agreement with the clinical diagnoses.

Patients judged unable to comply with the examination protocol were excluded. Informed consent was obtained from patients or their immediate relatives and the experimental protocol was approved by the ethics committee of the Neurology Department of the University of Bari.

Statistical analysis was performed with the Mann-Whitney $U$ test. transformation and zero order phase correction the areas under the peaks were obtained by numerical integration. Baseline correction was performed for the purpose of presentation. Postprocessing was always performed by the same investigator, who was unaware of the clinical diagnosis. Resonances were assigned as follows: Cho at $3.2 \mathrm{ppm}, \mathrm{Cr}$ at $3.0 \mathrm{ppm}$, NAA at $2.0 \mathrm{ppm}$, lac at $1.33 \mathrm{ppm} .{ }^{29}$ The selection of a long TE (135 ms) minimises potential signal contamination by lipids which

${ }^{1} H-M R S$ data

\begin{tabular}{llll}
\hline & $N A A / C h o$ & $N A A / C r$ & $C h o / C r$ \\
\hline IPD patients (8) & $1.89(0 \cdot 76)$ & $1.89(0.79)$ & $1.03(0.22)$ \\
PSP patients (5) & $1.27(0.25)^{\star \star}$ & $1.33(0.06)+\dagger$ & $1.08(0.20)$ \\
Controls & $1.97(0.59)^{\star \star}$ & $1.88(0.52)+\dagger$ & $0.97(0.15)$ \\
\hline
\end{tabular}

NAA/Cho $=\mathrm{N}$-acetyl-aspartate/choline; NAA/Cr $=\mathrm{N}$-acetyl-aspartate/creatine: $\mathrm{Cho} / \mathrm{Cr}$ $=$ choline/creatine; IPD = idiopathic Parkinson's disease; PSP = progressive supranuclear

$\underset{\star \star \mathrm{P}}{\text { palsy }}<0.01$ (Mann-Whitney); $+\mathrm{P}<0.01 v$ controls (Mann-Whitney).

\section{Results}

Fifteen spectra were obtained from the eight patients with idiopathic Parkinson's disease, seven from the five patients with progressive supranuclear palsy, and 13 from the nine control subjects. Figure 2 gives samples of the spectra. In all these instances, the quality of the spectra allowed the assessment of metabolite peaks. In some patients, abnormal peaks in However, they did not interfere with the measurement of NAA, Cho, and Cr peak areas.

The means (SD) of peak area ratios were: idiopathic Parkinson's disease group: NAA/Cho 1.89 (0.76), NAA/Cr 1.89 (0.79), Cho/Cr 1.03 (0.22); progressive supranuclear palsy group: NAA/Cho $1.27(0.25)$, NAA/Cr 1.33 (0.06), Cho/Cr 1.08 (0.20); control the lipid zone $(0.5-1.6 \mathrm{ppm})$ were detected. 

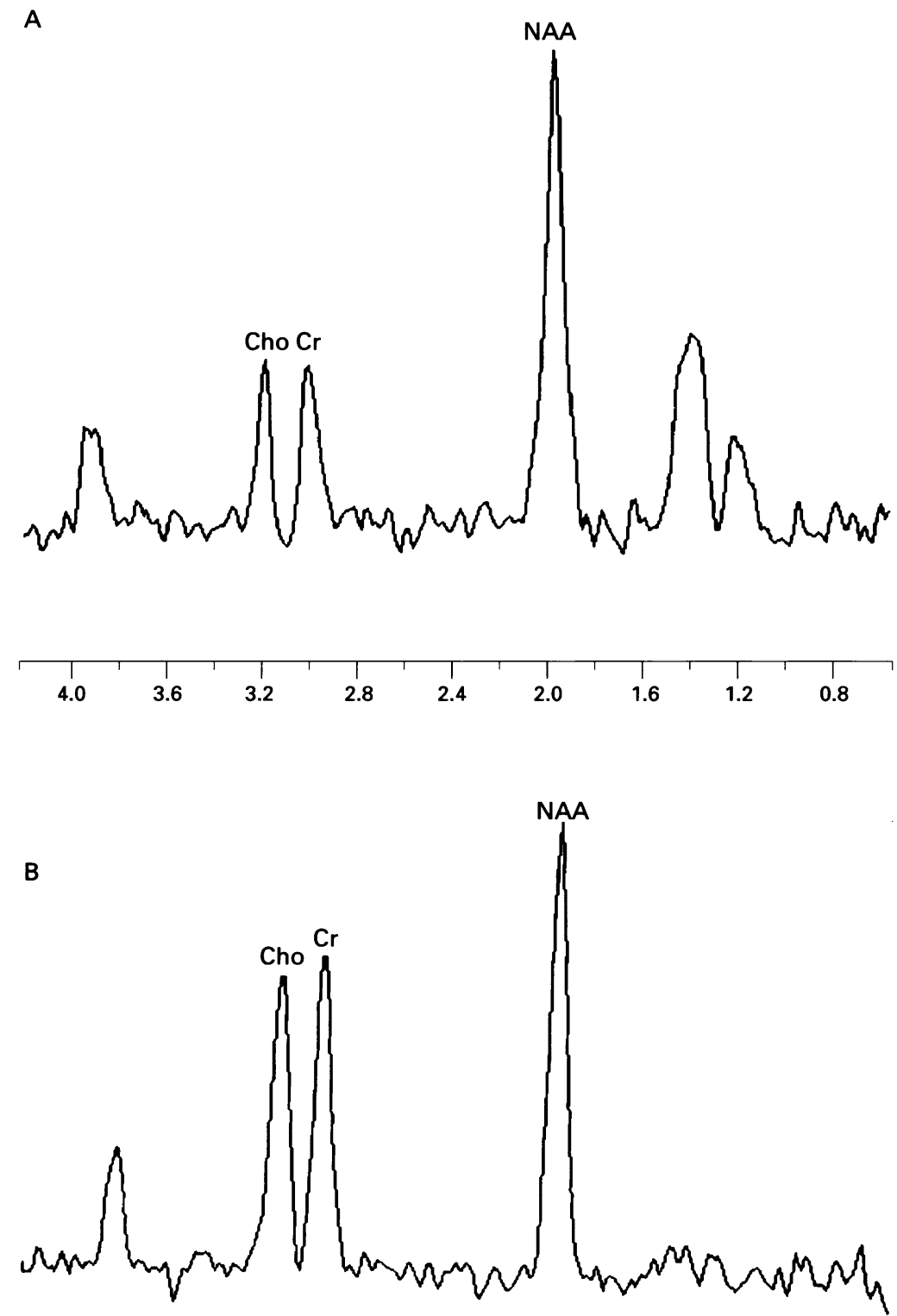

\begin{tabular}{|c|c|c|c|c|c|c|c|c|c|}
\hline & & & & & & & & & \\
4.0 & 3.6 & 3.2 & 2.8 & 2.4 & 2.0 & 1.6 & 1.2 & 0.8
\end{tabular}

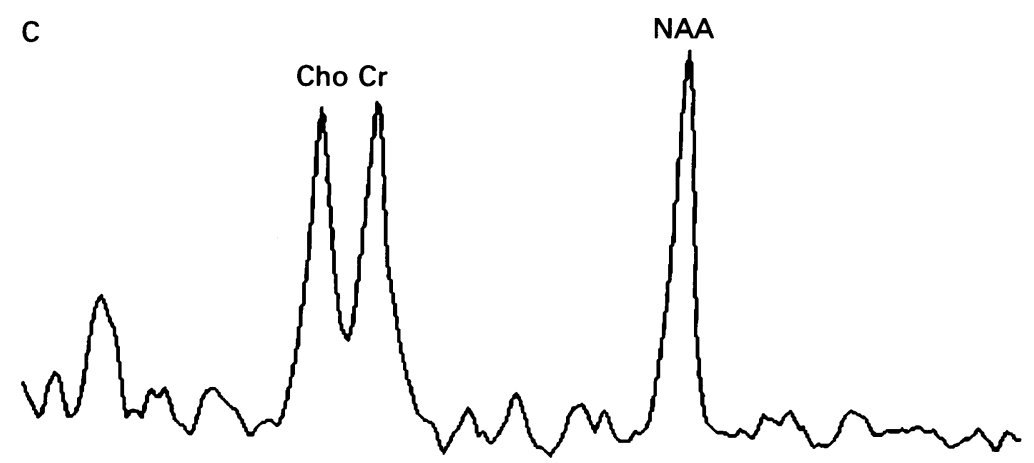

\begin{tabular}{|c|c|c|c|c|c|c|c|}
\hline 1 & ${ }_{36}$ & 1 & 1 & 1 & ${ }_{2}^{1}$ & 1 & 1 \\
\hline & & & hen & -0 & & & \\
\hline
\end{tabular}

Figure 2 'H-MRS spectra obtained from a control subject (top) and from two different patients, one with idiopathic Parkinson's disease (middle) and one with progressive supranuclear palsy (bottom); NAA/Cho and NAA/Cr ratios are decreased in patients with progressive supranuclear palsy. group: NAA/Cho 1.97 (0.59), NAA/Cr 1.88 (0.52), Cho/Cr $0.97(0 \cdot 15)$ (table).

Analysis of peak ratios did not show any significant differences between the left and the right side in any of the groups.

Statistical analysis disclosed a significant reduction of $\mathrm{NAA} / \mathrm{Cho}$ and $\mathrm{NAA} / \mathrm{Cr}$ ratios in patients with progressive supranuclear palsy compared with controls $(P<0.008$ in both cases).

\section{Discussion}

In this study ${ }^{1} \mathrm{H}-\mathrm{MRS}$ did not show any significant difference between patients with idiopathic Parkinson's disease and control subjects. This result is in agreement with previous reports. ${ }^{23} 26$ The NAA/Cho and NAA/Cr ratios were significantly reduced in patients with progressive supranuclear palsy compared with control subjects. A similar result was found by Davie et al in patients with multiple system atrophy. ${ }^{23}$ In our study we compared peak area ratios; this type of relative quantitation is currently a common way of expressing spectral information. ${ }^{8}$ The reduction of NAA/Cho and NAA/Cr ratios seems more likely due to a selective reduction of NAA level; in fact, the $\mathrm{Cr}$ peak is relatively stable and has been used as an internal standard in a previous study on basal ganglia; ${ }^{723}$ up to now it has been found to be reduced only in neoplastic and infectious diseases, or in association with a large reduction of NAA and Cho levels, in severe ischaemic lesions. ${ }^{716}$ Davie et al reported in patients with multiple system atrophy a reduction of the $\mathrm{Cho} / \mathrm{Cr}$ ratio, due to a Cho deficit. ${ }^{23}$ In our study, no patient group showed any significant difference in the $\mathrm{Cho} / \mathrm{Cr}$ ratio compared with controls. We hypothesise that in patients with progressive supranuclear palsy the reduction of NAA/Cho and NAA/Cr peak ratios could be due to a selective decrease in NAA levels, rather than to a contemporary increase of Cho and $\mathrm{Cr}$ levels. The reduction of NAA is also supported by the role of this metabolite, which is an amino acid confined in the brain only to neurons, and therefore usually considered as a marker of neuronal integrity. ${ }^{78}$ Thus in different types of neurological disease, the NAA deficit has been shown to be related to the extent of neuronal loss. ${ }^{79}$ In this study the reduction of $\mathrm{NAA} / \mathrm{Cr}$ and $\mathrm{NAA} / \mathrm{Cho}$ ratios was significant in patients with progressive supranuclear palsy, in whom neuronal loss involves the putamen and globus pallidus. Normal ${ }^{1} \mathrm{H}-\mathrm{MRS}$ data suggest a diagnosis of idiopathic Parkinson's disease, whereas low striatal levels of NAA could suggest a diagnosis of multiple system atrophy or progressive supranuclear palsy. This technique could therefore be useful for differentiating between these different clinical conditions in vivo. In fact $5 \%$ to $22 \%$ of patients diagnosed in life as having idiopathic Parkinson's disease show postmortem pathological findings of multiple system atrophy or progressive supranuclear palsy. 52331

The technique allowed us to detect lac as a 
doublet at $1.33 \mathrm{ppm}$. Lac peaks in our study were difficult to recognise because of the presence, in some patients, of wide base peaks between 0.5 and $1.6 \mathrm{ppm}$, of uncertain interpretation. These peaks, when present, did not interfere with the measurement of the three main metabolite peaks. These additional wide base peaks could be related to acyl chains of phospholipids and triglycerides. Usually these lipid compounds are absent in the brain, but can be detected in peroxisomal disorders. ${ }^{8}$ The presence of these lipid peaks could be related to lipofuscin storage in basal ganglia. ${ }^{25} 32$

In conclusion, the significant reduction of $\mathrm{NAA} / \mathrm{Cr}$ and NAA/Cho in the lentiform nucleus of patients with progressive supranuclear palsy seems to confirm in vivo the neuronal loss occurring in the globus pallidus of these patients. Further studies, in larger series, are necessary to better define the utility of ${ }^{1} \mathrm{H}$ MRS in this field. 'H-MRS may be a useful tool for the diagnosis and the pathogenetic interpretation of parkinsonian neurodegenerative disorders.

1 Golbe LI, Davis PH. Progressive supranuclear palsy. In: Jankovic J, Tolosa E, eds. Parkinson's disease and movement disorders. Baltimore-Munich: Urban, Schwarzenberg 1988:121-30.

2 Gibb WRG. The neuropathology of parkinsonian disorders. In: Jankovic J, Tolosa E, eds. Parkinson's disease and movement disorders. Baltimore-Munich: Urban, movement disorders.

3 Gouider-Khouja N, Vidailhet M, Bonnet AM, Pichon J, Agid Y. "Pure" striatonigral degeneration and Agid Y. "Pure" striatonigral degeneration and Parkinson's disease: a com
Disord 1995;10:288-94.

4 Agid Y. Parkinson's disease and cell death. Lancet 1991;337:1321-24.

5 Quinn N. Multiple system atrophy: the nature of the beast. f Neurol Neurosurg Psychiatry 1989;57(suppl):78-9.

6 Collins SJ, Ahlskog JE, Parisi JE, Maraganore DM. Progressive supranuclear palsy: neuropathologically based diagnostic clinical criteria. $\mathcal{f}$ Neurol Neurosurg Psychiatry 1995;58:167-73.

7 Miller BL. A review of chemical issues in 'H NMR spectroscopy: N-acetyl-L-aspartate, creatine and choline. NMR biomed 1991;4:47-52.

8 Vion-Dury J, Meyerhoff DJ, Cozzone PJ, Weiner MW. What might be the impact on neurology of the analysis of What might be the impact on neurology of the analysis of brain metabolism by in vivo magne

9 Frahm J, Michaelis T, Merboldt KD, Hanicke W, Gyngell ML, Bruhn $\mathrm{H}$. On the $\mathrm{N}$-acetyl methyl resonance in localized 'H-NMR spectra of human brain in vivo. NMR Biomed 1991;4:201-4.

10 Nadler JV, Cooper JR. N-acetyl-1-aspartic acid content of human neural tumours and bovine peripheral nervous tissues. F Neurochem 1972;19:213-9.

11 Veech RL. The metabolism of lactate. NMR Biomed 1991;4:53-8.

12 Bruhn H, Michaelis T, Merboldt KD, Hanicke W, Gyngell $M$, Hamburger C, Frahm J. On the interpretation of proton NMR spectra from brain tumours in vivo and in vitro. NMR Biomed 1992;5:253-8.

13 Fulham M, Bizi A, Dietz MJ, Shih HIH, Raman R, Sobering GS, et al. Mapping of brain tumor metabolites with proton MR spectroscopic imaging: clinical relevance. Radiology 1992;185:675-86.

14 Felber SR, Aichner FT, Sauter R, Gerstenbrand F. Combined magnetic resonance imaging and proton magnetic resonance spectroscopy of patients with acute stroke. Stroke 1992;23:1 106-10.

15 Gideon P, Henriksen O, Sperling B, Christiansen P, Skyho Olsen T, Jorgensen HS, Arlien-Soborg P. Early time course of $\mathrm{N}$-acetyl-aspartate, creatine and phosphocreatine and compounds containing choline in the brain after acute stroke. A proton magnetic resonance spectroscopy study. Stroke 1992;23:1566-72.

16 Federico F, Simone IL, Conte C, Lucivero V, Giannini P, Liguori $M$, et al. Prognostic significance of metabolic changes detected by proton magnetic resonance specchanges detected by proton magnetic resonance spec-

17 Matthews PM, Francis G, Amel J, Arnold DL. Proton magnetic resonance spectroscopy for metabolic characterization of plaques in multiple sclerosis. Neurology 1991;41:1251-6.

18 Arnold DL, Matthews PM, Francis GS, O'Connor J, Antel JP. Proton magnetic resonance spectroscopic imaging for metabolites characterization of demyelinating plaques. Ann Neurol 1992;31:235-41.

19 Chang L, Miller BL, Mc Bride D, Cornford M, Oropilla G, Buchtal S, et al. Brain lesions in patients with AIDS: $\mathrm{H}-1$ MR spectroscopy. Radiology 1995;197:525-31.

20 Barker PB, Lee RR, Mc Arthur JC. AIDS dementia complex: evaluation with proton MR spectroscopic imaging. Radiology 1995;195:58-64.

21 Jenkins BG, Koroshetz WJ, Beal MF, Rosen BR. Evidence for impairment of energy metabolism in vivo in Huntington's disease using localized 'H NMR specHuntington's disease using localized

22 Shonk TK, Moats RA, Gifford P, Michaelis T, Mandigo JC, Izumi J, Ross BD. Probable Alzheimer disease: diagnosis with proton MR spectroscopy. Radiology 1995; 195:65-72.

23 Davie CA, Wenning GK, Barker GJ, Tofts PS, Phil D, Kendall BE, et al. Differentiation of multiple system atrophy from idiopathic Parkinson's disease using proton magnetic resonance spectroscopy. Ann Neurol 1995; 37:204-10.

24 Davie CA, Pirtosek Z, Barker GJ, Kingsley DPE, Miller PH, Lees AJ. Magnetic resonance spectroscopic study of parkinsonism related to boxing. $f$ Neurol Neurosurg Psychiatry 1995;58:688-91.

25 Bowen BC, Block RE, Sanchez-Ramos J, Pattany PM, Wampman DA, Murdoch JB, Quencer RM. Proton MR Lampman DA, Murdoch JB, Quencer RM. Proton MR

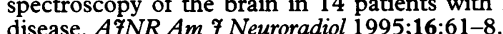

26 Holshouser NA, Komu M, Moller HE, Zijlmans J, Kolem $\mathrm{H}$, Hinshaw Jr DB, et al. Localized proton NMR spectroscopy in the striatum of patients with idiopathic Parkinson's disease: a multicenter pilot study. Magn Reson Med 1995;33:589-94.

27 Lemmens G, Ray Chaudhuri K, Williams S, Ellis C, Leigh PN. Proton magnetic resonance spectroscopy (PMRS) in idiopathic Parkinson's disease. Neurology 1995;45(suppl 4):A317.

28 Michaelis T, Merboldt KD, Hanicke W, Gyngell M, Bruhn $\mathrm{H}, \mathrm{Frahm} \mathrm{J}$. On the identification of cerebral metabolites in localized ' $H$-NMR spectra of human brain in vivo. NMR Biomed 1991;4:47-52.

29 Frahm J, Bruhn H, Gyngell ML, Merboldt KD, Hanicke W, Sauter R. Localized H-NMR spectroscopy in different regions of the human brain in vivo: relaxation times ent regions of the human brain in vivo: relaxation times and concentrations of

30 Golbe LI, Davis PH, Schonberg BS, Duvoisin RC. Prevalence and natural history of progressive supranuclear palsy. Neurology 1988;8:1031-4.

31 Rajput A H, Marsden C D. The motor disorder of multiple system atrophy. Can $\mathcal{F}$ Neurol Sci 1991;18:275-8.

32 Barbeau A. Parkinson's disease: clinical features and etiopathology. In: Vinken PJ, Bruyn GW, Klawans HL, eds. Handbook of clinical neurology, vol 5 (49): extrapyramidal disorders. Amsterdam: Elsevier Science Publishers B $\mathrm{V}, 1986: 87-152$. 